\title{
O AUMENTO ABUSIVO DE PREÇOS REFERENTE A UTENSÍLIOS E MEDICAMENTOS EM TEMPOS DE PANDEMIA
}

\author{
Mariana Boechat da Costa ${ }^{1}$
}

\begin{abstract}
RESUMO: O presente trabalho visa analisar o aumento abusivo de preços referente a utensílios e medicamentos em tempos de pandemia. Sob esse viés, será realizada uma pesquisa qualitativa, por meio da análise da legislação, doutrina e documentos escritos. Inicialmente serão tecidos comentários sobre a crise em curso e os seus impactos socioeconômicos. Em seguida será realizada uma abordagem teórica sobre o Código de Defesa do Consumidor à luz do Direito Econômico. Sequencialmente será abordada a tutela do consumidor sob a perspectiva da Lei Antitruste e do Código Consumerista. Por fim, serão explanadas as medidas necessárias para o reequilíbrio do sistema econômico-financeiro.
\end{abstract}

Palavras-chave: Práticas abusivas; Mercado de consumo; Lei Antitruste; Intervenção do Estado; Pandemia.

\section{THE ABUSIVE INCREASE IN PRICES FOR UTENSILS AND MEDICINES IN PANDEMIC TIMES}

\begin{abstract}
The present paper seeks to analyze the abusive price increase related to utensils and medicines in times of pandemic. Under this bias, a qualitative research will be carried out, through the analysis of legislation, doctrine and written documents. Initially, comments will be made on the ongoing crisis and socioeconomic impacts. Then, a theoretical approach on the Consumer Protection Code will be carried out in the light of Economic Law. Sequentially, consumer protection will be addressed from the perspective of the Antitrust Law and the Consumer Code. Finally, the necessary measures to rebalance the economic and financial system will be explained.
\end{abstract}

Keywords: Abusive practices; Consumer market; Antirust Law; State intervention; Pandemic.

\section{INTRODUÇÃO}

Diante do atual cenário de crise global econômica e social, ocasionado pela magnitude dos efeitos do novo coronavírus (Covid-19), as relações de consumo foram alvo de práticas abusivas, em que fornecedores de produtos e serviços - referentes a utensílios e medicamentos

\footnotetext{
${ }^{1}$ Mestranda em Direito Econômico e Desenvolvimento pela Universidade Candido Mendes, unidade Centro/RJ. Pós-graduada em Direito Público e Privado pela Escola da Magistratura do Estado do Rio de Janeiro. E-mail: maryboechatdacosta@gmail.com. Currículo lattes: https://wwws.cnpq.br/cvlattesweb/PKG_MENU.menu?f_cod=4CA78712F748690965BC0F19317F1D5C.
} 
do setor de saúde - aumentaram demasiadamente os seus valores. Os consumidores tiveram a sua liberdade de escolha restringida, à medida que foram coagidos a se submeter a preços extorsivos para sanar suas necessidades básicas.

Nessa senda, destaca-se o teor do art. 39 do Código de Defesa do Consumidor, o qual versa sobre condutas reprováveis, que uma vez constatadas devem ser repelidas, dentre estas destaca-se a elevação de preços de produtos e serviços sem justa causa. No presente caso, tornase evidente o ato abusivo, pois devido à crise pandêmica o aumento de valores não configura justo motivo, mas sim uma insensibilidade para com os mandamentos emanados da solidariedade social.

Cumpre ressaltar que a livre concorrência tem previsão expressa no art. 36, caput, inciso I, da Lei n. 12.529/2011 (Lei Antitruste) e no art. 170, caput, inciso IV, da Constituição Federal. Sendo assim, é assegurado aos agentes a liberdade de desenvolvimento de atividade econômica. Entretanto, limites à sua atuação são impostos, moldando o seu comportamento no mercado. Entende-se que ao mesmo tempo que a Lei Antitruste protege a livre inciativa e a livre concorrência, tutela-se também o consumidor, impedindo que a ele sejam impostos preços excessivos, mediante o aumento arbitrário de preços.

Considerando o panorama atual, a pesquisa proposta tem como objetivo geral identificar as práticas abusivas ocorridas no mercado de consumo durante o período pandêmico. No tocante ao objetivo específico, o estudo visa estabelecer medidas efetivas para salvaguardar o direito dos consumidores e estimular o crescimento econômico. Nesse sentido, será analisada a competência do Conselho Administrativo de Defesa Econômica (CADE). Além disso, será abordada a edição da Medida Provisória nº 933 de 2020, que suspende, pelo prazo de sessenta dias, o ajuste anual de preços de medicamentos para o ano de 2020.

Quanto à metodologia, será realizada uma pesquisa qualitativa, por meio do método investigativo analítico-descritivo, para a observação de normas, doutrinas e documentos escritos. Serão obtidas fontes primárias e secundárias por meio de arquivos públicos, particulares, programas investigativos, entre outros, os quais serão analisados e interpretados com vista à elaboração de um estudo descritivo.

\section{A PANDEMIA DA COVID-19 E OS SEUS IMPACTOS SOCIOECONÔMICOS}


O Coronavírus, Covid-19 ou SARS-CoV-2 - sua nomenclatura oficial - significa Síndrome Respiratória Aguda grave de Coronavírus 2. O termo SARS-Cov-2 se refere ao agente causador da pandemia de SARS, ocorrida no ano de 2002. Ambas terminologias decorrem de uma família viral já conhecida desde a década de 1960.

Apesar de parecidos e causadores de infecções respiratórias, a peculiaridade do Coronavírus de 2019 se dá pela ausência de um padrão reconhecível pela medicina, o que dificulta o tratamento de pacientes e ocasiona vastas incertezas médico-científicas no período de tratamento.

O primeiro caso desta doença foi notificado no dia 31 de dezembro de 2019 por autoridades chinesas que observaram diversos casos de pneumonia na cidade de Wuhan. A origem da primeira transmissão ainda é incerta, mas há suspeita de que tenha sido originada por alimentação humana de animal silvestre, como a cobra ou o morcego. ${ }^{2}$

Os sintomas do novo vírus foram identificados como febre, tosse, dificuldade em respirar e falta de ar. Em casos mais graves, há registro de pneumonia, insuficiência renal e síndrome respiratória aguda grave. Os mais vulneráveis são os idosos e os portadores de doenças crônicas, como diabetes, hipertensão e asma, em que há possibilidade de maiores complicações.

A grande preocupação decorre da elevada velocidade em que o vírus se propaga, atingindo, no momento, cerca de 66 milhões de infectados ao redor do mundo e 1.531 .488 mortos. No Brasil, segundo dados do Governo Federal, a taxa de letalidade é de 3,0\% dos casos confirmados $^{3}$, tendo, no presente momento, mais de 6.577 .177 de pessoas contaminadas e 176.641 mortes pela doença. ${ }^{4}$ Devido ao alto impacto da Covid-19, os sistemas de saúde alertaram para o risco de colapso, uma vez que não possuem estrutura suficiente para suportar uma demanda em alta escala.

O Brasil, seguindo as orientações da OMS, decretou medidas de contenção da doença, como a restrição de locomoção e o fechamento do comércio e de serviços. A principal forma de conter a proliferação do vírus está baseada na prevenção. Desse modo, com a autorização da União, os governos dos Estados e Municípios receberam autonomia para dispor acerca das

2 CORONAVÍRUS: o que se sabe sobre o novo vírus que surgiu na China. Disponível em: $<$ https://g1.globo.com/bemestar/coronavirus/noticia/2020/02/27/o-que-se-sabe-e-o-que-ainda-e-duvida-sobre-ocoronavirus.ghtml>. Acesso em: 27 set. 2020.

${ }^{3}$ Segundo notícia veiculada em: https://covid.saude.gov.br/. Acesso em: 26 set. 2020.

4 CORONAVÍRUS: o mapa que mostra o alcance mundial da doença. Disponível em: <https://www.bbc.com/portuguese/internacional-51718755>. Acesso em: 28 set. 2020. 
medidas de seguranças regionais, de acordo com a peculiaridade de cada local, levando sempre em consideração o número de casos confirmados.

Nesse sentido, diversas foram as decisões do Poder Executivo a nível estatual, que variaram desde a obrigatoriedade do uso de máscaras, limitação de locomoção, suspensão geral das atividades em estabelecimentos diversos - flexibilizada de acordo com a diminuição de vítimas locais - além de medidas de higiene pessoal e distanciamento social.

A ampliação das medidas restritivas trouxe rapidamente inúmeros impactos econômicos, visto que a produção, os investimentos e o consumo corrente foram tremendamente abalados. Constatou-se a escassez de diversos produtos, tais como medicamentos e equipamentos na área da saúde, o que acarretou um aumento desproporcional dos preços de mercado.

Em virtude disso, tornou-se necessária a busca por medidas capazes de estimular o setor econômico sem, contudo, desrespeitar o direito dos consumidores e as relações contratuais já entabuladas. Sendo assim, surge a necessidade de se analisar o Código de Defesa do Consumidor de forma conjunta ao Direito Econômico.

\section{O CÓdIGO DE DEFESA DO CONSUMIDOR SOB A ÓTICA DO DIREITO ECONÔMICO}

O direito econômico teve origem na década de 1920, após a primeira guerra mundial. É conhecido como o ramo do Direito que tem o objetivo de regulamentar as atividades econômicas ocorrentes do mercado, definindo parâmetros e limites para as empresas públicas e privadas, por intermédio de uma política econômica de concretização de ditames e princípios constitucionais.

Nas palavras de Iedo Batista Neves (1997, p. 811), o direito econômico é considerado como o "conjunto de regras que protegem as relações de ordem jurídica que resultam da produção, circulação, distribuição e consumo das riquezas”.

As regras do direito econômico encontram-se amparadas constitucionalmente. O art. 170 da Constituição Federal de $1988^{5}$, como forma de preservar e concretizar direitos, adotou

\footnotetext{
${ }^{5}$ Art. 170 - a ordem econômica, fundada na valorização do trabalho humano e na livre iniciativa, tem por fim assegurar a todos existência digna, conforme os ditames da justiça social, conforme os ditames da justiça social, observados os seguintes princípios: (...) IV- livre concorrência; V- defesa do consumidor (...).
} 
a garantia do exercício dos direitos sociais e individuais, a proteção da cidadania e da dignidade da pessoa humana, a defesa dos interesses dos consumidores e o princípio da ordem econômica e financeira.

Nesse sentido, observa-se que o direito econômico tem como fim a concretização, a fruição e o exercício dos direitos sociais, estabelecendo, portanto, metas para que sejam alcançadas e cumpridas no plano infraconstitucional. Para tanto, torna-se necessária a criação de normas, regras, institutos e características, pois só assim será possível a regulamentação jurídica da política econômica adotada pela Constituição Federal.

Dessa forma, dispõe o artigo 170 da Constituição Federal de 1988 "a ordem econômica, fundada na valorização do trabalho humano e na livre iniciativa, tem por fim assegurar a todos existência digna, conforme os ditames da justiça social". Denota-se, assim, a consagração de uma economia de mercado pautada em uma natureza capitalista, embora não se negue a prioridade aos valores do trabalho humano com vistas a alcançar a justiça social. Logo, a liberdade econômica não possui um cunho absoluto, sendo garantida até onde o fundamento e a finalidade da ordem econômica não sejam ameaçados.

Nesse sentido, cumpre ressaltar a questão elementar referente ao conflito distributivo da remuneração do trabalho e do capital. Thomas Piketty entende que a desaceleração demográfica, bem como a desaceleração do crescimento econômico contribuem para a piora na distribuição de renda. Sendo assim, com a chegada do século XXI, observa-se que a estrutura de renda e riqueza dos países estão contribuindo para que os rendimentos e a remuneração do capital avancem. Entretanto, por outro lado, as taxas de crescimento econômico tendem a encolher.

(...) a evolução dinâmica de uma economia de mercado e de propriedade privada, deixada à sua própria sorte, contém forças de convergência importantes, ligadas sobretudo à difusão d o conhecimento e das qualificações, mas também forças de divergências vigorosas e potencialmente ameaçadoras para nossas sociedades democráticas e para os valores de justiça social sobre os quais elas se fundam. (PIKETTY, 2014, p. 692)

A Magna Carta de 1988, nos moldes do art. $5^{\circ}$, XXXII, consagrou a proteção jurídica do consumidor, incorporando em suas normas programáticas a tendência do Direito Público moderno, in verbis: “O Estado promoverá, na forma da lei, a defesa do consumidor". No mesmo sentido, o art. 170, inciso V da Carta Política eleva a defesa do consumidor a princípio geral da 
ordem econômica. Com o intuito de materializar a mencionada proteção jurídica, em 11 de setembro de 1990 veio à lume a lei no 8.078 - conhecida como o Código de Defesa do Consumidor (CDC).

O supracitado diploma legal constitui-se em uma poderosa ferramenta de cidadania. Normas de proteção são estabelecidas em favor da parte mais vulnerável de uma relação de consumo - o consumidor. Isso se dá devido ao forte desequilíbrio da relação contratual entre o fornecedor e o consumidor, impondo, assim, a implementação de medidas capazes de estabelecer um equilíbrio entre esses mesmos sujeitos. A ratio essendi do Código de Defesa do Consumidor é declarar a sua vulnerabilidade, por ser considerado o polo mais fraco da relação.

Diante disso, é imperioso destacar o prestígio que as garantias de defesa da figura constitucional do consumidor possuem no ordenamento jurídico, uma vez que, "numa sociedade capitalista como a nossa, inserida no contexto histórico do capitalismo moderno, passa a ser dever do Estado a sua proteção”. (CANOTILHO, 2013, p. 19.38)

O Código de Defesa do Consumidor é considerado um microssistema, pois a lei principiológica afasta toda e qualquer norma jurídica da mesma hierarquia que com ela conflite sem revogá-la. Nesse sentido, na lição de Sérgio Cavalieri Filho (2019, p. 359) o CDC possui uma "sobre-estrutura jurídica multidisciplinar, aplicável em toda e qualquer área do direito onde ocorrer uma relação de consumo". Além disso, assume uma dimensão coletiva, visto que é composto por normas de ordem pública e de interesse social.

Dessa forma, o mencionado diploma legal possui normas de ordem pública e de interesse social, portanto, versa sobre direitos indisponíveis, ensejando uma observância de ofício. Diante de um mundo globalizado e de uma sociedade absolutamente formada por relações contratualistas, o CDC visa à equiparação dos sujeitos que integram uma relação jurídica de consumo, com o fim de reconhecer a vulnerabilidade, lato sensu, do consumidor frente ao fornecedor.

Vale ressaltar, que coibir abusos é um dos objetivos do Direito Econômico, com fulcro a harmonizar os interesses dos sujeitos da atividade econômica presentes no mercado com os princípios constitucionais consagrados no art. $5^{\circ}$, XXXII (direito e garantia fundamental à defesa dos interesses dos consumidores), art. 170, IV e V (defesa do consumidor como princípio geral da ordem econômica) e no art. 173, § $4^{\circ}$ (repressão ao abuso do poder econômico).

Portanto, as regras do direito econômico amparam-se na ideologia constitucionalmente adotada e exprimem-se por meio das medidas de política econômica traçada. Movem-se como 
fonte subsidiária para a concretização dos direitos assegurados constitucionalmente, como os direitos e garantias fundamentais pautados na proteção e na defesa dos interesses dos consumidores (art. $5^{\circ}$, XXXII). Conclui-se, assim, que o grau de civilidade de uma nação pode ser aferido pela análise e proteção conferida aos seus consumidores.

\section{A TUTELA DO CONSUMIDOR SOB A PERSPECTIVA DA LEI ANTITRUSTE E DO CÓDIGO CONSUMERISTA}

A livre concorrência encontra-se, de forma expressa, no art. 36, caput, inciso I da Lei n. $12.529 / 2011^{6}$ (Lei Antitruste) e no art. 170, caput, inciso IV, da CF $^{7}$. Sendo assim, é assegurado aos agentes a liberdade de desenvolvimento de atividade econômica. Entretanto, limites à sua atuação são impostos, moldando o seu comportamento no mercado.

Nessa senda, compreende-se que a liberdade de iniciativa não conflita com a necessidade de atuação estatal, uma vez que esta objetiva a manutenção e preservação do sistema econômico, com fulcro a evitar crises. Nesse sentido, o art. $173 \S 4^{\circ}$, da CF, dispõe que: “a lei reprimirá o abuso do poder econômico que vise à dominação dos mercados, à eliminação da concorrência e ao aumento arbitrário de preços."

Cumpre ressaltar que o art. 36 caput, inciso III, da Lei n. 12.529/2011 ${ }^{8}$, proíbe o aumento arbitrário de lucros do agente econômico, independente da posição dominante por ele detida. O objetivo pretendido é a proteção do consumidor, ou daqueles explorados frente aos agentes dominantes. "Desde há muito, encontra-se nos diplomas brasileiros antitruste, bem

\footnotetext{
${ }^{6}$ Art. 36. Constituem infração da ordem econômica, independentemente de culpa, os atos sob qualquer forma manifestados, que tenham por objeto ou possam produzir os seguintes efeitos, ainda que não sejam alcançados: I limitar, falsear ou de qualquer forma prejudicar a livre concorrência ou a livre iniciativa.

${ }^{7}$ Art. 170. A ordem econômica, fundada na valorização do trabalho humano e na livre iniciativa, tem por fim assegurar a todos existência digna, conforme os ditames da justiça social, observados os seguintes princípios: IVlivre concorrência.

8 Art. 36. Constituem infração da ordem econômica, independentemente de culpa, os atos sob qualquer forma manifestados, que tenham por objeto ou possam produzir os seguintes efeitos, ainda que não sejam alcançados: III - aumentar arbitrariamente os lucros.
} 
como nas normas constitucionais, a repressão aos lucros arbitrários ou aos preços excessivos correlatos ao abuso do poder econômico, tendo em vista a proteção da população, dos consumidores". (FORGIONI, 2015, p. 140)

Entende-se que ao mesmo tempo que a Lei Antitruste protege a livre inciativa e a livre concorrência, tutela-se também o consumidor, impedindo que a ele sejam impostos preços excessivos, mediante o aumento arbitrário de preços. Ou seja, a livre iniciativa não permite que o agente estabeleça preços de forma aleatória e sem critérios, de modo a prejudicar os consumidores.

\begin{abstract}
O lucro é permitido e primordial numa economia capitalista, mas não pode transbordar para o abuso, para a exploração dos consumidores, sobretudo dos mais incautos. Exemplo típico dessa prática abusiva era o famigerado ágio cobrado por concessionárias na venda de veículos novos quando o mercado estava aquecido. A principal finalidade da vedação dessa prática é assegurar o equilíbrio contratual, impedindo que o fornecedor, utilizando-se de sua condição de superioridade econômica, cause prejuízo ao consumidor. (CAVALIERI, 2019, p. 195)
\end{abstract}

De outro modo, sabe-se que o art. 39 do Código de Defesa do Consumidor elenca as práticas abusivas relativas ao fornecimento de produtos e serviços. Constata-se, nesse cenário, o ápice da vulnerabilidade sofrida pelo consumidor na relação de consumo, pois este encontrase em uma situação de desvantagem, caracterizada por um ato ilícito, qual seja - o abuso de direito.

O ato abusivo é constituído pela ausência da boa-fé e da lealdade perante "um direito subjetivo lícito atribuído ao titular, que, ao exercê-lo, o torna antijurídico" (GARCIA, 2010, p. 248), ocasionando, ou não, lesão a outrem. Significa dizer, que o fornecedor, justificando-se na competitividade do mercado, alarga a condição de vulnerabilidade do consumidor ao extrapolar o exercício dos seus direitos.

Nessa linha, o ato abusivo se torna evidente quando não há um fundamento para o aumento demasiado de uma oferta, que contém efeito vinculante para o fornecedor, ocorrendo, assim, o desrespeito as demais regras aplicáveis às relações de consumo, conforme o art. 39, inciso X, da Lei $\mathrm{n}^{\text {o }} 8.078$ de $1990 .^{9}$

De fato, existem hipóteses que justificam a elevação extraordinária nos preços, como o aumento no preço do insumo do bem; o aumento na qualidade do produto; o reajuste no preço em razão da inflação; o aumento razoável do preço com fins de aumentar o lucro. Ocorre que

\footnotetext{
${ }^{9}$ Art. 39. É vedado ao fornecedor de produtos ou serviços, dentre outras práticas abusivas: X - Elevar sem justa causa o preço de produtos ou serviços.
} 
devido aos transtornos gerados pela Covid-19, a significativa elevação dos preços não configura justa causa, mas sim uma insensibilidade para com os mandamentos emanados da solidariedade social.

Dando seguimento à discussão em pauta e tratando, especificamente, do aumento abusivo de preços referente a utensílios e medicamentos no período da pandemia, cabe discutir a dimensão dessa prática entre os fornecedores de produtos e serviços, observando quais os desdobramentos e implicações dessas ações na sociedade de consumo.

Nesse sentido, deve-se registrar, segundo o Procon/SC o aumento abusivo de valores cobrados por parte dos fornecedores na venda de produtos para a Secretaria da Saúde do Governo de Santa Catarina. O sobrepreço chega a 56\% nos insumos para a área. Diversas notas de diferentes fornecedores mostram que antes do surto da Covid-19 as máscaras eram adquiridas por $\mathrm{R} \$ 4,80$ a unidade. Agora os valores subiram para $\mathrm{R} \$ 29,90 .{ }^{10}$

Igualmente, a Federação dos Hospitais, Clínicas e laboratórios do Estado de São Paulo divulgou levantamento no qual aponta o aumento de mais de $1.000 \%$ em insumos hospitalares. Uma caixa com 50 unidades de máscara tripla com elástico, que custava $R$ \$,50 em janeiro deste ano, aumentou para $\mathrm{R} \$ 140,00$ no dia 17 de março. Outro produto citado é a luva descartável, uma caixa com 200 pares custava $R$ \$ 14,70 em fevereiro, e agora R $\$ 22,00$. Já o cateter 22 , era vendido a $\mathrm{R} \$ 0,65$, atualmente é encontrado na faixa de $\mathrm{R} \$ 2,46$ a unidade. Uma ampola de $40 \mathrm{mg}$ de Omeprazol que custava $\mathrm{R} \$ 5,72$, passou a custar R $\$ 15,20$. O Berotec de $20 \mathrm{ml}$, também, teve o valor aumentado de $\mathrm{R} \$ 2,45$ para $\mathrm{R} \$ 13,25{ }^{11}$

Em um momento de profunda comoção - em que o país sofre progressivamente os efeitos negativos da Covid-19 - constatam-se práticas ilegais no mercado de consumo, uma vez que alguns fornecedores de produtos e serviços estão se aproveitando da situação de crise e de impotência dos consumidores para taxá-los com preços exorbitantes, em um cenário que o espírito da solidariedade deveria prevalecer.

Nesse sentido, o aumento injustificado no preço de produtos e serviços vai de encontro aos objetivos e princípios da Política Nacional das Relações de Consumo, em especial, o princípio da boa-fé, conforme previsão expressa do art. $4^{\circ}$, III do CDC:

\footnotetext{
${ }^{10}$ SILVA, Anderson. Coronavírus: parte dos fornecedores da Saúde está cobrando valores abusivos, segundo o Procon de SC. Disponível em: <https://www.nsctotal.com.br/colunistas/anderson-silva/coronavirus-parte-dosfornecedores-da-saude-esta-cobrando-valores>. Acesso em: 29 jul. 2020.

11 PEDUZZI, Pedro. Insumos hospitalares registram aumentos acima de 1.000\%. Disponível em: $<$ https://agenciabrasil.ebc.com.br/saude/noticia/2020-03/insumos-hospitalares-registram-aumentos-acima-de1000>. Acesso em: 05 set. 2020.
} 


\begin{abstract}
Art. $4^{\circ}$ A Política Nacional das Relações de Consumo tem por objetivo o atendimento das necessidades dos consumidores, o respeito à sua dignidade, saúde e segurança, a proteção de seus interesses econômicos, a melhoria da sua qualidade de vida, bem como a transparência e harmonia das relações de consumo, atendidos os seguintes princípios:

(...)

III - harmonização dos interesses dos participantes das relações de consumo e compatibilização da proteção do consumidor com a necessidade de desenvolvimento econômico e tecnológico, de modo a viabilizar os princípios nos quais se funda a ordem econômica (art. 170, da Constituição Federal), sempre com base na boa-fé e equilíbrio nas relações entre consumidores e fornecedores. (grifos nossos).
\end{abstract}

Os casos relacionados ao aumento abusivo de preços, em momento de calamidade, não são prerrogativas do Brasil. Nos Estados Unidos - especificamente na Flórida no ano de 2006 - o furacão Charley deixou em seu rastro uma discussão sobre preços extorsivos. Michael Sandel (2019) em seu best-seller, "Justiça: o que é fazer a coisa certa", exorta o leitor a refletir se é justo que comerciantes cobrem valores excessivos por seus produtos diante de situações de emergência.

Na época, o procurador-geral da Flórida - Charlie Crist publicou um texto em um jornal de Tampa defendendo a lei contra o abuso de preços. Repudiou veemente a ideia de que preços "inescrupulosos" estejam presentes sob pretexto de um comércio verdadeiramente livre. Consumidores sob coação não têm liberdade, agem com o único intuito de sanar suas necessidades básicas. Em suas palavras:

Não se trata de uma situação normal de livre mercado, na qual pessoas que desejam
comprar algo decidem livremente entrar no mercado e encontram pessoas dispostas a
vender-lhes o que desejam, na qual um preço obedece à lei da oferta e da procura.
Numa situação de emergência, compradores coagidos não têm liberdade. A compra
de artigos básicos e a busca de abrigo seguro são algo que lhes é imposto. (CRIST,
2004, p. 17).

A situação supracitada trouxe à baila outras questões morais relacionadas ao bom funcionamento de uma sociedade, como o espírito da solidariedade, a virtude cívica e o bemestar social. Nesse sentido:

Em tempos de dificuldades, uma boa sociedade se mantém unida. Em vez de fazer pressão para obter mais vantagens, as pessoas tentam se ajudar mutuamente. Uma sociedade na qual os vizinhos são explorados para a obtenção de lucros financeiros em tempos de crise não é uma sociedade boa. A ganância excessiva é, portanto, um vício que a boa sociedade deve procurar desencorajar, na medida do possível. As leis do abuso de preços podem não pôr fim à ganância, mas podem ao menos restringir sua expressão descarada e demonstrar o descontentamento da sociedade. Punindo o 
comportamento ganancioso ao invés de recompensá-lo, a sociedade afirma a virtude cívica do sacrifício compartilhado em prol do bem comum. (SANDEL, 2019, p. 17)

No Brasil é comum a reiteração de práticas abusivas em situações calamitosas. Cabe relembrar o ocorrido no caso Brumadinho/MG, após o rompimento de barragens de rejeito de mineração da Vale. À época foram registradas práticas reprováveis por parte de alguns comerciantes que se aproveitaram da escassez de oferta e do aumento da procura pela água para elevar, demasiadamente, o preço do produto. (BRANDOLIN, 2019)

Diante do cenário atual, torna-se necessária a elaboração de medidas governamentais que busquem conter, de forma efetiva, a prática abusiva de elevação injustificada de preços de produtos essenciais em período de extrema crise.

\section{MEDIDAS NECESSÁRIAS PARA O REEQUILÍBRIO DO SISTEMA ECONÔMICO-FINANCEIRO}

O Estado neoliberal é pautado nos princípios da livre iniciativa e da livre concorrência, ou seja, os empresários têm a liberdade de ingressarem e permanecerem no mercado para exercerem sua atividade econômica. De igual modo, é facultado a estes a perfeita utilização de todos os recursos lícitos para que desenvolvam da melhor maneira a sua atividade. Assim, a livre concorrência possibilita que o mercado selecione os profissionais mais bem capacitados para fornecer seus produtos e serviços de forma diferenciada à clientela.

Nessa seara, percebe-se que a livre concorrência garante a sobrevivência do mercado. Este encontra-se livre às leis da oferta e da procura, não havendo imposições ou restrições quanto ao número de empresas de um mesmo setor que busquem conquistar o seu espaço. Podese entender, que os mercados sem restrições se baseiam em duas premissas - uma sobre bemestar e outra sobre liberdade. Nesse sentido:

\footnotetext{
A defesa usual dos mercados sem restrições baseia-se em duas postulações — uma sobre bem-estar, outra sobre liberdade. Primeiro, os mercados promovem o bem-estar da sociedade como um todo por meio de incentivos para que as pessoas se esforcem a fim de fornecer as mercadorias que as outras desejam. (No dizer comum, frequentemente equiparamos o bem-estar à prosperidade econômica, embora bemestar seja um conceito mais amplo, que pode incluir aspectos não econômicos do bemestar social.) Em segundo lugar, os mercados respeitam a liberdade individual; em vez de impor um determinado valor às mercadorias e serviços, deixam que as pessoas escolham por si mesmas que valor atribuir ao que compram e vendem (SANDEL, 2019, p. 14).
} 
Entretanto, ao nos aprofundarmos no tema, encontramos algumas objeções sobre a existência de um mercado totalmente livre. Como é sabido, existem regras mínimas e limites estabelecidos que interferem na liberdade individual de escolha. Ocorre, que essas interferências nem sempre são percebidas, na maioria das vezes passam de forma despercebida. Nesse sentido:

\begin{abstract}
Todo mercado tem algumas regras e limites que restringem a liberdade de escolha. $\mathrm{O}$ mercado só parece livre porque estamos tão condicionados a aceitar as suas restrições subjacentes que deixamos de percebê-las. Não é possível definir objetivamente o quanto um mercado é "livre". Essa é uma definição política. A alegação habitual dos economistas que defendem o livre mercado de que eles estão tentando defender o mercado contra a interferência politicamente motivada do governo é falsa. O governo está sempre envolvido e esses adeptos do livre mercado estão tão politicamente motivados quanto qualquer pessoa. Superar o mito de que existe algo como um "livre mercado" objetivamente definido é o primeiro passo na direção de entender o capitalismo. (CHANG, 2013, p. 16).
\end{abstract}

Seguindo tal propositura, o artigo 173, $\S 4^{\circ}$ da Magna Carta, ressalta que a lei com o intuito precípuo de reprimir o abuso do poder econômico que vise à dominação dos mercados, à eliminação da concorrência e o aumento arbitrário dos lucros poderá por intermédio do Estado intervir no domínio econômico. Assim sendo:

\begin{abstract}
A livre concorrência está configurada no art. 170, IV, como um dos princípios da ordem econômica. Ele é uma manifestação da liberdade de iniciativa e, para garanti-la, a Constituição estatui que a lei reprimirá o abuso de poder econômico que vise à dominação dos mercados, à eliminação da concorrência e ao aumento arbitrário dos lucros. Os dois dispositivos se complementam no mesmo objetivo. Visam tutelar o sistema de mercado e, especialmente, proteger a livre concorrência contra a tendência açambarcadora da concentração capitalista. (AFONSO DA SILVA, 1998, p.876) (grifos nossos).
\end{abstract}

A intervenção estatal na ordem econômica ocorre quando o Estado se vale de medidas capazes de impor condições na iniciativa privada, com o intuito de proporcionar bem-estar social às pessoas, bem como fomentar a economia do país. Além disso, a intervenção requer planejamento e programação, assim como o respeito aos direitos e garantias individuais previstos constitucionalmente. Nesse sentido:

A intervenção na ordem econômica, assim como as demais atividades administrativas, depende do planejamento prévio por parte do Estado. Trata-se de um dever (e não de mera liberalidade do Estado) cujo objetivo é garantir o Direito Fundamental à Boa Administração Pública. O planejamento público pode ser conceituado como a programação que tem por propósito selecionar objetivos, indicar meios e definir as metas que deverão ser implementadas pela atuação estatal. Em virtude da pluralidade 
de interesses públicos, que devem ser satisfeitos pelo Estado, e da escassez de recursos financeiros, o planejamento é fundamental para escolhas racionais das prioridades públicas. (OLIVEIRA, 2017, p. 700).

Denota-se, assim, um papel mais ativo do poder público nas irregularidades do mercado, como forma de gerar benefícios para à coletividade.

\begin{abstract}
Aos agentes é assegurada liberdade de desenvolvimento de atividade econômica, e, para garantir a manutenção do sistema e das regras do jogo, são impostos limites à atuação desses mesmos agentes, disciplinando seu comportamento no mercado. A disciplina da concorrência, então, coloca-se como correlata à livre iniciativa. (FORGIONI, 2015, p. 271).
\end{abstract}

Cumpre ressaltar que a teoria econômica convencional entende que as intervenções do Estado são admitidas apenas para corrigir falhas de mercado. Entretanto, torna-se importante a necessidade de se construir uma teoria do papel do Estado na formação e criação de mercados. Sendo assim, "não basta falar do "Estado empreendedor", é preciso construí-lo - prestando atenção a organizações e instituições concretas no governo que conseguem criar estratégias de crescimento no longo prazo e "dar as boas-vindas" aos inevitáveis fracassos." (MAZZUCATO, 2014, p. 229)

Merece destaque, no entanto, a capacidade do governo em fazer escolhas corretas e fomentar a economia de um país. As melhores soluções não são prerrogativas de empresas privadas. O setor público tem condição de obter informações precisas e agir da melhor maneira para conter crises e abusos. Em muitos casos, isso se torna possível por intermédio de iniciativas conjuntas entre o setor público e o privado, originando a criação de empresas estatais e de agências reguladoras. Nesse sentido:

Os governos são capazes de fazer boas escolhas, às vezes escolhas espetaculares. Se olharmos em volta com a mente aberta, veremos muitos exemplos no mundo inteiro de governos que fizeram escolhas bem-sucedidas. $\mathrm{O}$ argumento de que as decisões do governo que afetam as empresas comerciais certamente serão inferiores às decisões tomadas pelas próprias empresas é injustificável. Ter informações mais detalhadas não garante melhores decisões; na realidade, pode ser mais difícil tomar a decisão certa quando estamos envolvidos demais com a situação. Além disso, existem maneiras pelas quais o governo pode obter melhores informações e melhorar a qualidade das suas decisões. Além do mais, decisões que são boas para empresas individuais podem não ser boas para a economia nacional como um todo. Por conseguinte, o fato de o governo escolher vencedores contrariando os sinais do mercado pode melhorar o desempenho econômico nacional, especialmente se isso for feito em estreita (porém não excessiva) colaboração com o setor privado. (CHANG, 2013, p. 105). 
Nessa seara, destaca-se o Conselho Administrativo de Defesa Econômica (CADE), uma autarquia federal, vinculada ao Ministério da Justiça, com sede e foro no Distrito Federal. Sua principal missão é zelar pela livre concorrência no mercado, sendo a entidade responsável, no âmbito do Poder Executivo, não só por investigar e decidir, em última instância, sobre a matéria concorrencial, como também fomentar e disseminar a cultura da livre concorrência. ${ }^{12}$ Além disso, é considerado um órgão político, uma vez que não possui o elemento da imparcialidade.

Cabe ressaltar que a defesa da concorrência não se faz exclusivamente no âmbito do CADE, mas também na esfera judicial, conforme o art. 47 da Lei 12.529/2011 ${ }^{13}$. Outro ponto de destaque, refere-se ao fato de as decisões do CADE estarem amplamente sujeitas ao controle judicial. Torna-se importante pontuar a existência de críticas no tocante a esta possibilidade de revisão, uma vez que as decisões são discricionárias em razão da expertise do órgão. ${ }^{14}$ Entretanto, a revisão judicial é a segurança do cidadão contra eventuais abusos ou enganos realizados pelo Poder executivo, conforme preconiza o art. $5^{\circ}$, inciso XXXV, da CF. ${ }^{15}$

Diante da pandemia da Covid-19, em 18 de março de 2020, o CADE instaurou o procedimento preparatório de Inquérito Administrativo $\mathrm{n}^{\circ}$ 08700.001354/2020-48 para verificar se empresas do setor de saúde estão aumentando preços e obtendo lucros de forma abusiva. Nas palavras do Superintendente Geral, Alexandre Cordeiro Macedo, o procedimento em questão foi instaurado:

\footnotetext{
${ }^{12}$ As atribuições do CADE estão previstas na Lei no 12.529 , de 30 de novembro de 2011. A autarquia exerce três funções: Preventiva - analisar e posteriormente decidir sobre as fusões, aquisições de controle, incorporações e outros atos de concentração econômica entre grandes empresas que possam colocar em risco a livre concorrência; Repressiva - investigar, em todo o território nacional, e posteriormente julgar cartéis e outras condutas nocivas à livre concorrência; Educativa - instruir o público em geral sobre as diversas condutas que possam prejudicar a livre concorrência; incentivar e estimular estudos e pesquisas acadêmicas sobre o tema, firmando parcerias com universidades, institutos de pesquisa, associações e órgãos do governo; realizar ou apoiar cursos, palestras, seminários e eventos relacionados ao assunto; editar publicações, como a Revista de Direito da Concorrência e cartilhas. Disponível em: http://www.cade.gov.br/acesso-a-informacao/institucional/copy_of_competencias/capainterna. Acesso em: 30 ago. 2020.

${ }^{13}$ Art. 47. Os prejudicados, por si ou pelos legitimados referidos no art. 82 da Lei no 8.078, de 11 de setembro de 1990, poderão ingressar em juízo para, em defesa de seus interesses individuais ou individuais homogêneos, obter a cessação de práticas que constituam infração da ordem econômica, bem como o recebimento de indenização por perdas e danos sofridos, independentemente do inquérito ou processo administrativo, que não será suspenso em virtude do ajuizamento de ação.

${ }^{14}$ Sua atuação baseia-se no corte horizontal da realidade, uma vez que a este cabe analisar os mais diversos setores com dinâmicas e características peculiares.

${ }^{15}$ Art. $5^{\circ}$ Todos são iguais perante a lei, sem distinção de qualquer natureza, garantindo-se aos brasileiros e aos estrangeiros residentes no País a inviolabilidade do direito à vida, à liberdade, à igualdade, à segurança e à propriedade, nos termos seguintes: XXXV- a lei não excluirá da apreciação do Poder Judiciário lesão ou ameaça a direito.
} 
(...) tendo em vista a situação de elevada demanda por produtos médicosfarmacêuticos em decorrência da necessidade cuidados emergenciais motivados pelo aumento de casos relacionados à Covid-19, empresas do setor de saúde podem estar aumentando os preços e lucros de forma arbitrária e abusiva, sendo necessário, por parte do Cade, zelar para que tais abusos, se efetivamente verificados, sejam punidos com base no artigo 36, I, III e IV, com as penas cominadas nos arts. 37 e 38, todos da Lei $n^{\circ} .12 .259 / 2011 .{ }^{16}$

Assim, serão investigados hospitais, laboratórios, farmácias, fabricantes e distribuidores de produtos como máscaras cirúrgicas, álcool gel, além de responsáveis pela produção de medicamentos para o tratamento da Covid-19. Essas empresas deverão apresentar, em até 10 dias, notas fiscais dos produtos.

Dessa forma, compete ao CADE investigar e punir supostas condutas de práticas abusivas, nos moldes do art. 36, I, III e IV, 37 e 38 da Lei no 12.529 de 2011. Caso sejam constatadas violações, as companhias poderão ser punidas por infração à ordem econômica, em sanções que podem chegar a multa de $20 \%$ do faturamento bruto da firma, bem como o impedimento de celebrar negócios com o Poder Público.

Outra medida de combate, refere-se à edição da Medida Provisória no 933 de $2020^{17}$ que suspende, pelo prazo de sessenta dias, o ajuste anual de preços de medicamentos para o ano de 2020 - previsto na Lei $\mathrm{n}^{\circ} 10.742$ de 2003. A preocupação gira em torno da incapacidade de milhares de famílias de adquirirem os medicamentos necessários ao combate da doença, pois estamos em um cenário de instabilidade econômica ocasionado por uma crise sanitária. Desse modo, os medicamentos necessitam ter os seus reajustes suspensos, enquanto durar a pandemia, para viabilizar aos brasileiros - principalmente aos mais vulneráveis - o amplo acesso.

Portanto, cumpre ressaltar que a intervenção do Estado na economia é legítima e está respaldada no art. 174 da Constituição Federal, que confere competência ao Estado como agente normativo e regulador da atividade econômica, exercendo, na forma da lei, as funções de fiscalização, incentivo e planejamento.

\section{CONCLUSÃO}

\footnotetext{
${ }^{16}$ Procedimento Preparatório de Inquérito Administrativo. Processo no 08700.001354/2020-48. Disponível em: $<$ https://sei.cade.gov.br/sei/modulos/pesquisa/md_pesq_documento_consulta_externa.php?DZ2uWeaYicbuRZE FhBt-n3BfPLlu9u7akQAh8mpB9yN5-g_g0O9zChGsgE5Z_2H25KowY3t3BnzFcJrkIPBprQu1Xz4OKIIq5iTVR2wdQK10M8ZmoD1NL3vg3xjWq5f>. Acesso em: 07 set. 2020.

17 Para mais informações, vide: https://www.congressonacional.leg.br/materias/medidas-provisorias//mpv/141347. Acesso em: 08 set. 2020.
} 
Como se observou ao longo deste estudo, o aumento injustificado de preços em tempos de pandemia é considerado uma prática abusiva no mercado de consumo. Fornecedores de produtos e serviços se valem da vulnerabilidade dos consumidores, em situação de extrema necessidade para taxá-los de forma exorbitante.

Partindo desta premissa inicial, constatou-se que cabe ao Estado intervir na ordem econômica para coibir abusos e proporcionar o bem-estar social. O art. 174 da Constituição Federal estabelece que como agente normativo e regulador da atividade econômica, o Estado exercerá, na forma da lei, as funções de fiscalização, incentivo e planejamento.

Destaca-se, assim, a competência do CADE para investigar e punir supostas condutas abusivas, podendo aplicar multas de até $20 \%$ do faturamento bruto da firma, bem como o impedimento de celebrar negócios com o Poder Público. Nesse sentido, foi instaurado um procedimento preparatório de inquérito administrativo para verificar se empresas do setor de saúde estão aumentando preços e obtendo lucros de forma abusiva.

Por outro giro, identificou-se como forma de contenção de práticas abusivas, a edição da Medida Provisória n 933 de 2020, que suspende, pelo prazo de sessenta dias, o ajuste anual de preços de medicamentos para o ano de 2020. O objetivo desta medida é viabilizar aos brasileiros, principalmente aos mais vulneráveis, o amplo acesso a medicamentos necessários ao combate da Covid-19.

Dentro deste contexto, conclui-se que o governo é um elemento essencial para gerar crescimento econômico, maior estabilidade e níveis mais aceitáveis de justiça. Posto isto, como forma de coibir abusos em tempos de crise, o Estado deve investir em um melhor sistema regulatório e em políticas públicas eficientes.

\section{REFERÊNCIAS}

BRANDOLIN, Luciana Picanço de Oliveira. Indústria e Desastre: os legados de Mariana e Brumadinho. Rio de Janeiro: Resumapas, 2019.

Código de Defesa do Consumidor. Disponível em: <http://www.planalto.gov.br/ccivil_03/leis/18078.htm>. Acesso em: 25 ago. 2020. 
BRASIL. Constituição da República Federativa do Brasil. Disponível em: <http://www.planalto.gov.br/ccivil_03/Constituicao/Constituicao.htm>. Acesso em: 15 set. 2020.

. Lei $\mathrm{n}^{\mathrm{o}}$ 12.529, de 30 de novembro de 2011. Disponível em: <http://www.planalto.gov.br/ccivil_03/_ato2011-2014/2011/lei/112529.htm>. Acesso em: 02 jul. 2020.

Medida Provisória no 933 de 2020 (em tramitação). Disponível em: https://www.congressonacional.leg.br/materias/medidas-provisorias/-/mpv/141347.Acesso em 09 jun. 2020.

CANOTILHO, J. J. Gomes; et al. Comentários à constituição do Brasil. São Paulo: Saraiva, 2013.

CAVALIERI FILHO, Sérgio. Programa de Direito do Consumidor. 5. ed. São Paulo: Atlas, 2019.

CHANG, Ha-Joo. 23 coisas que não nos contaram sobre o capitalismo. Tradução Claudia Gerpe Duarte. São Paulo: Cultrix, 2013.

CORONAVÍRUS: o mapa que mostra o alcance mundial da doença. Disponível em: <https://www.bbc.com/portuguese/internacional-51718755>. Acesso em: 28 set. 2020.

: o que se sabe sobre o novo vírus que surgiu na China. Disponível em: <https://g1.globo.com/bemestar/coronavirus/noticia/2020/02/27/o-que-se-sabe-e-o-que-aindae-duvida-sobre-o-coronavirus.ghtml>. Acesso em: 27 set. 2020.

CRIST, Charlie. Storm Victimis Need Protection. Tampa Tribune, Florida, p. 17, set. 2004.

FORGIONI, Paula. Os fundamentos do antitruste. 8. ed. São Paulo: Revista dos Tribunais, 2015.

GARCIA, Leonardo. Direito do consumidor: código comentado e jurisprudência. 6. ed. Niterói: Impetus, 2010.

MAZZUCATO, Mariana. O Estado empreendedor: desmascarando o mito do setor público vs. setor privado. São Paulo: Portfolio-Penguin, 2014.

NEVES, Iedo Batista. Vocabulário Enciclopédico de Terminologia Jurídica e de Brocardos Latinos. Rio de Janeiro: Forense, 1998.

OLIVEIRA, Rafael. Curso de Direito Administrativo. 5. ed. São Paulo: Método, 2017.

PEDUZZI, Pedro. Insumos hospitalares registram aumentos acima de 1.000\%. Disponível em: $<$ https://agenciabrasil.ebc.com.br/saude/noticia/2020-03/insumos-hospitalares-registramaumentos-acima-de-1000>. Acesso em: 5 set. 2020.

PIKETTY, Thomas. O capital do século XXI. Rio de Janeiro: Intrínseca, 2014. 
SANDEL, Michael. Justiça: o que é fazer a coisa certa. Tradução Heloísa Matias e Maria Alice Máximo. 26. ed. Rio de Janeiro: Civilização Brasileira, 2019.

SILVA, Anderson. Coronavírus: parte dos fornecedores da Saúde está cobrando valores abusivos, segundo o Procon de SC. Disponível em: $<$ https://www.nsctotal.com.br/colunistas/anderson-silva/coronavirus-parte-dos-fornecedoresda-saude-esta-cobrando-valores>. Acesso em: 29 jul. 2020.

SILVA, José Afonso. Curso de Direito Constitucional Positivo. 15. ed. São Paulo: Malheiros, 1998. 